\title{
Changes of salivary antioxidant enzymes during hematopoietic cell transplantation: implications to oral mucositis and xerostomia

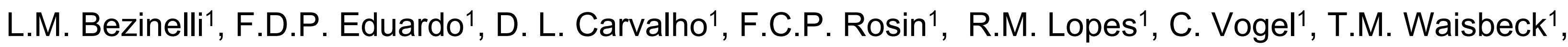
N. Hamerschlak ${ }^{1}$, L. Correa².

${ }^{1}$ Hospital Israelita Albert Einstein, Hematology, Sao Paulo, Brazil.

${ }^{2}$ School of Denstitry- University of São Paulo, General Pathology Department, Sao Paulo, Brazil.

Introduction: The aim of this study was to investigate the levels of salivary antioxidant enzymes during hematopoietic cell transplantation (HCT), and their association with oral toxicity.

Methods: Stimulated saliva of patients who underwent autologous and allogeneic HCT $(n=72)$ was collected at baseline (T0, before the HCT), neutropenia (T1), and after marrow engraftment (T2). Activity of superoxide dismutase (SOD) and levels of catalase (CAT) and glutathione reductase $(G R)$ in the saliva were also determined. Association tests of these enzymes with oral mucositis and xerostomia were performed.

Characteristics of the patients

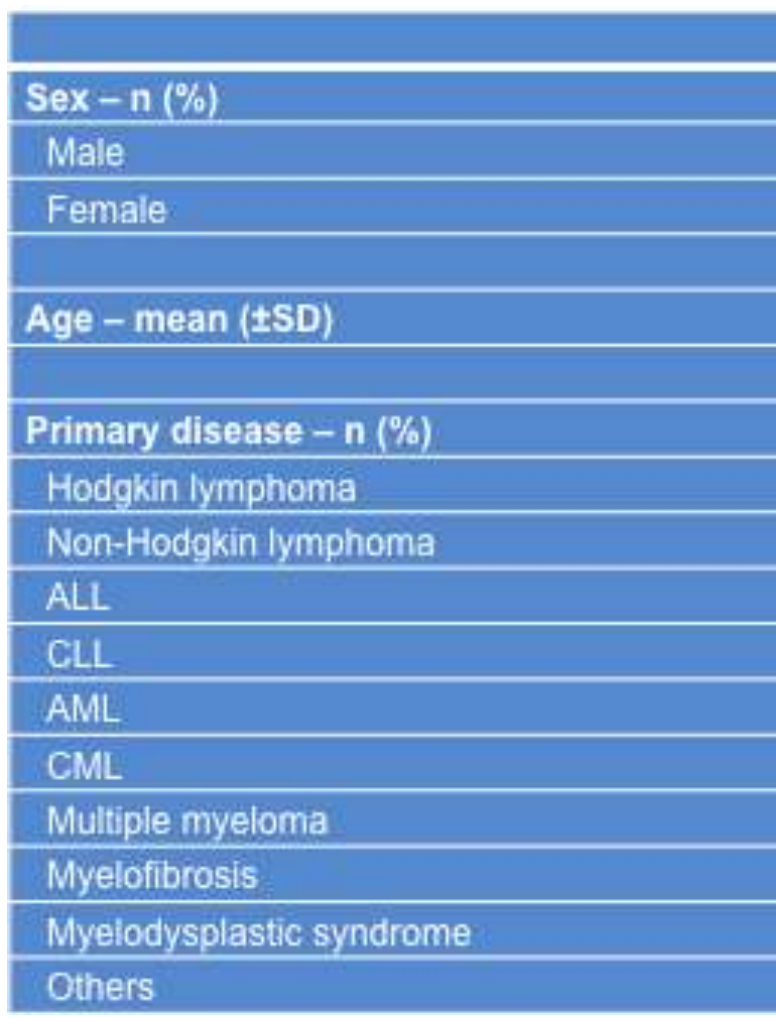

\begin{tabular}{|c|}
\hline Total $(n=72)$ \\
\hline $38(52.8)$ \\
\hline $34(47.2)$ \\
\hline $46.0 \pm 17.2$ \\
\\
\hline \\
\hline $4(5.6)$ \\
$16(22.2)$ \\
$5(6.9)$ \\
$1(1.4)$ \\
$7(9.7)$ \\
$4(5.6)$ \\
$12(16.7)$ \\
$3(4.2)$ \\
$6(8.3)$ \\
$14(19.4)$ \\
\hline
\end{tabular}

\section{Characteristics of the transplantation.}

\begin{tabular}{|c|c|}
\hline & Total $(n=72)$ \\
\hline \multicolumn{2}{|l|}{ Type of transplantation } \\
\hline Autologous & $35(48.6)$ \\
\hline Allogeneic & $23(31.9)$ \\
\hline Haploidentical & $14(19.4)$ \\
\hline \multicolumn{2}{|l|}{ Conditioning $-\mathrm{n}(\%)$} \\
\hline Bu/FIu (tiotepa, ATG or TMI) & $19(26.4)$ \\
\hline $\mathrm{Bu} / \mathrm{Cy}$ & $4(5.6)$ \\
\hline Bu/Mel & $1(1.4)$ \\
\hline MeliFlu/TBI & $8(11.1)$ \\
\hline Mel & $12(16.7)$ \\
\hline Cy/Eto/Mel & $2(2.8)$ \\
\hline BEAMR-BEAM & $15(20.8)$ \\
\hline Cy/Flu/TBI & $6(8.3)$ \\
\hline Cy/methilprednisolone/ATG & $3(4.2)$ \\
\hline Flu/TBI & $2(2.8)$ \\
\hline
\end{tabular}

Results:
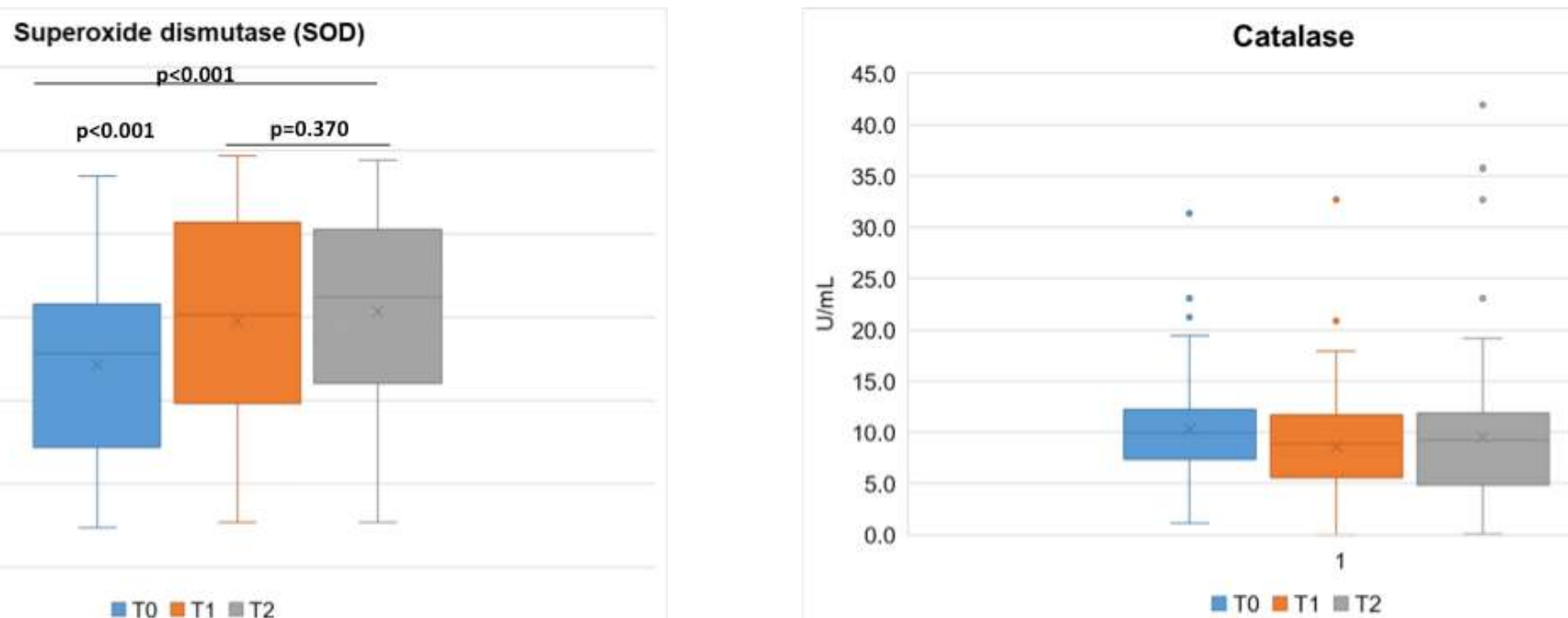

$17(23.6)$

$10(13.9)$

$5(6.9)$

$5(6.9)$

$11.6 \pm 6.0$

$4.4 \pm 3.0$
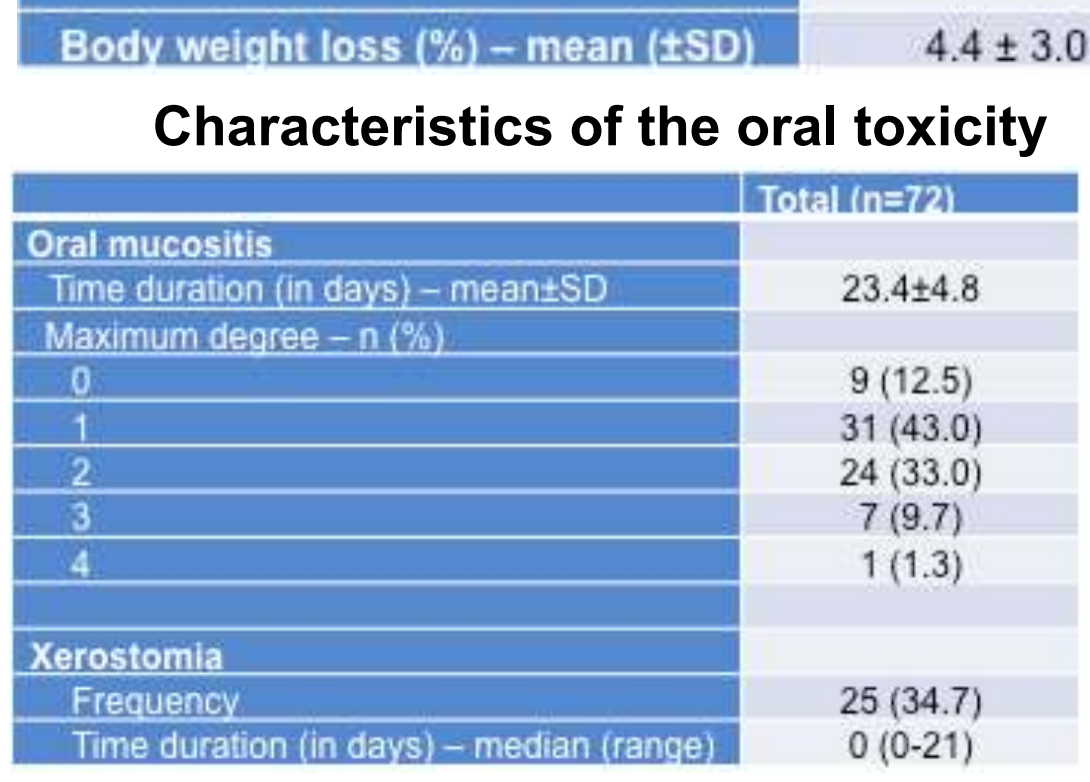

Gluthatione reductase

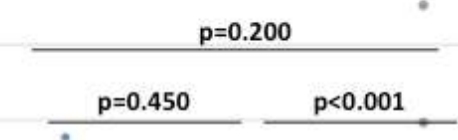

Logistic regression analysis with oral mucositis as dependent variable and antioxidative enzymes (at T1 $)^{\star}$ as independent variables.

\begin{tabular}{|l|l|l|l|}
\hline \multicolumn{1}{|c|}{$\begin{array}{c}\text { Duration of oral } \\
\text { mucositis }\end{array}$} & OR & Cl 95\% & P value \\
\hline First model & & & \\
\hline Catalase & 1.92 & $0.89-4.11$ & 0.095 \\
\hline Gluthatione reductase & 0.65 & $0.30-1.40$ & 0.274 \\
\hline Superoxide dismutase & 0.38 & $0.17-0.82$ & 0.001 \\
\hline Second model & & & \\
\hline Superoxide dismutase & 0.45 & $0.21-0.93$ & 0.031 \\
\hline
\end{tabular}

Logistic regression analysis with xerostomia as dependent variable and antioxidative enzymes (at T1) ${ }^{\star}$ as independent variables.

\begin{tabular}{|l|l|l|l|}
\multicolumn{1}{|c|}{ Xerostomia } & OR & Cl $95 \%$ & P value \\
\hline First model & & & \\
Catalase & 0.47 & $0.21-1.05$ & 0.066 \\
\hline Gluthatione reductase & 2.42 & $1.07-5.52$ & 0.034 \\
\hline $\begin{array}{l}\text { Superoxide dismutase } \\
\text { Second model }\end{array}$ & 2.91 & $1.30-6.51$ & 0.009 \\
\hline Gluthatione reductase & 2.30 & $1.03-5.15$ & 0.042 \\
\hline Superoxide dismutase & 2.55 & $1.17-5.52$ & 0.017 \\
\hline
\end{tabular}

Logistic regression analysis with oral mucositis as dependent variable and antioxidative enzymes (at TO)* as independent variables.

\begin{tabular}{|l|l|l|l|}
\hline \multicolumn{1}{|c|}{ Xerostomia } & OR & Cl $95 \%$ & P value \\
\hline First model & & & \\
\hline Catalase & 0.84 & $0.40-1.75$ & 0.650 \\
\hline Gluthatione reductase & 1.91 & $0.76-4.78$ & 0.166 \\
\hline $\begin{array}{l}\text { Superoxide dismutase } \\
\text { Second model }\end{array}$ & 2.48 & $1.18-5.25$ & 0.017 \\
\hline Superoxide dismutase & 2.71 & $1.32-5.55$ & 0.006 \\
\hline
\end{tabular}

Logistic regression analysis with xerostomia as dependent variable and antioxidative enzymes (at T2)* as independent variables.

\begin{tabular}{|l|c|c|c|}
\multicolumn{1}{|c|}{ Xerostomia } & OR & CI 95\% & P value \\
\hline First model & & & \\
\hline Catalase & 0.43 & $0.17-1.05$ & 0.064 \\
\hline Gluthatione reductase & 2.79 & $0.98-7.93$ & 0.053 \\
\hline $\begin{array}{l}\text { Superoxide dismutase } \\
\text { Second model }\end{array}$ & 4.84 & $1.93-12.10$ & $<0.001$ \\
\hline $\begin{array}{l}\text { Superoxide dismutase } \\
\text { S }\end{array}$ & 3.39 & $1.50-7.65$ & 0.003 \\
\hline
\end{tabular}

Conclusion: Expression patterns of salivary SOD, CAT, and GR during HCT periods are different, with a trend to SOD activity increase and CAT and GR reduction. SOD activity increase is related to a long duration of oral mucositis and xerostomia, suggesting that some protective antioxidant activity persists even in conditions of intense oral toxicity.

Ackwoledgments: We thank the São Paulo Research Foundation (FAPESP, Proc. \# 2016/03650-4) and AmigoH for their financial support. 